\title{
FAMILIA Y ENFERMEDADES EMERGENTES. Modelos de atención y representaciones culturales de la fiebre chikungunya entre la población maya
}

\author{
Paola PENICHE MORENO': Gabriel ANGELOTTI PASTEUR ${ }^{2}$ \\ ${ }^{1}$ CIESAS-Unidad Peninsular, Yucatán; ${ }^{2}$ Universidad Autónoma de Yucatán (México) \\ ppeniche@yahoo.com,gabrielotti@yahoo.com
}

\begin{abstract}
FAMILY AND EMERGING DISEASES. Models of health care and cultural representations of Chikungunya fever among the Mayan population
\end{abstract}

Resumen: Desde la perspectiva de la antropología médica, en este trabajo se abordan las prácticas implementadas por las familias mayas de una comunidad rural en México, para afrontar la epidemia de fiebre chikungunya que se vivió por primera ocasión en el año de 2015. El análisis se presenta siguiendo dos ejes centrales: 1) los modelos de atención preponderantes y su grado de articulación (autoatención, medicina tradicional, biomedicina), 2) las representaciones y explicaciones culturales configuradas en torno a este padecimiento hasta entonces desconocido. La base empírica se construyó a partir de registros etnográficos levantados durante la epidemia. Se rescatan las experiencias familiares, sus testimonios, argumentos y explicaciones; y se observa en la práctica la puesta en marcha de distintos modelos de atención. La herramienta metodológica empleada fue la "carrera curativa", identificando formas de atención desde las familias. Se concluye que a nivel práctico el principal modelo de atención frente a esta enfermedad emergente fue la autoatención (con énfasis en el uso de medicamentos), pero subordinada ideológicamente $-\mathrm{y}$, al mismo tiempo, sancionada- por el modelo biologicista.

Abstract: From the perspective of medical anthropology, this paper addresses practices of mayan families in a rural community in Mexico, implemented to deal chikungunya fever epidemic experienced for the first time in 2015. The analysis is presented following two central approaches: 1) prevailing care models and their degree of articulation (self-care, traditional medicine, biomedicine), 2) cultural representations around this previously unknown disease. The empirical data is constructed from ethnographic records raised during the epidemic. Emphasis is stressed on families experiences, testimonies, arguments and explanations; and different medical models are observed in practice. The main methodological tool was the "illness career" identifying, from families experiences, different forms of health care. It is concluded that the main model against this emerging disease, at the practical level, was selfcare (with emphasis on medicalization), but ideologically subordinate to the biologic model.

Palabras clave: Enfermedades Transmisibles Emergentes (EH). Familia (EH). Atención. Características Culturales. Grupos Étnicos

Communicable Disease. Emerging (EH). Family (EH). Attention. Cultural Characteristics. Ethnic Groups 


\section{Introducción}

Entre julio y diciembre de 2015, en el estado de Yucatán (México) se registró por primera ocasión una epidemia de fiebre de chikungunya. Se trata de una enfermedad infecciosa de origen viral (arbovirosis) transmitida por el mosquito Aedes aegypti, principalmente. ${ }^{1}$ Sus signos y síntomas característicos son fiebre alta, dolor articular, muscular y de cabeza, además de salpullido en todo el cuerpo. ${ }^{2}$ A pesar de que las cifras oficiales de la Dirección General de Epidemiología reportaron en un inicio muy pocos casos, lo que personalmente pudimos observar apuntaba en otro sentido, tanto en la ciudad de Mérida como en localidades mayas del interior del Estado. En efecto, la Secretaría de Salud a nivel estatal pronto se vio rebasada por los índices de contagio, y la falta de información y atención fue mucho más sensible y palpable en el área rural -predominantemente indígena (maya). A nivel oficial se reconoció la incapacidad de los centros de salud para atender a la gran cantidad de enfermos que reclamaban atención, y tan pronto en agosto se anunció una escasez general de paracetamol (acetaminofén) y de reactivos de laboratorio para hacer el análisis específico para detectar el virus. ${ }^{3}$

Este contexto sirvió para investigar las prácticas implementadas por las familias mayas de una comunidad rural para afrontar esta enfermedad emergente, siguiendo dos ejes centrales: 1) los modelos de atención médica preponderantes y su grado de articulación (auto-atención, medicina tradicional, biomedicina), 2) las representaciones y explicaciones culturales configuradas en torno a este padecimiento hasta entonces desconocido. La base empírica para este trabajo se construyó a partir de entrevistas abiertas y cerradas realizadas durante los meses en los que se presentó la epidemia, entre julio y diciembre del 2015.

\section{Marco conceptual}

Cuando hablamos de "modelo" nos referimos, como propone Menéndez (2009), a una abstracción que nos permite abarcar de la realidad, compleja y diversa, diferentes formas de atención que tienen su propia historicidad y se vinculan con determinadas racionalidades: 1) El Modelo Médico Hegemónico presenta como rasgos característicos el biologicismo, que es ahistórico e individualista, que concibe a la salud como una mercancía (en términos directos o indirectos), que tiende a establecer una relación asimétrica entre curadores y pacientes; supone a su vez la existencia de tres submodelos, el modelo médico corporativo público, el modelo médico individual privado y el modelo corporativo privado; 2) El Modelo Médico Subordinado, integra a las prácticas generalmente conocidas como "tradicionales"; en este caso, se trata de la medicina tradicional maya que se identifica con un pasado y corresponde con una cosmovisión específica. En ningún caso los modelos se conciben como estáticos, y parte del proceso en el cual se ha visto envuelta la medicina tradicional maya ha sido precisamente su subordinación con el modelo hegemónico biologicista, tanto en términos ideológicos, como económicos e incluso jurídicos. Otro de sus rasgos característicos es que tiene una concepción globalizadora de los padecimientos, y que sus acciones terapéuticas requieren de la sociabilidad y la eficacia simbólica; 3) el Modelo de Autoatención, en el que el diagnóstico y atención son llevados a cabo por la propia persona o personas inmediatas de sus grupos familiares o comunales; este modelo supone el primer nivel real de atención y en él no actúa directamente un curador profesional. Además de las funciones

\footnotetext{
1 Aunque también por el Aedes albopictus (Setbon y Raude, 2016: 491), ambos presentes en México (Ibáñez y Gómez, 1995).

2 Síntomas descritos por la Organización Panamericana de la Salud, en: http://www.paho.org/hq/index. php?option=com_content $\&$ view=article\&id=8303\&Itemid=40023\&lang=es

3 Ver por ejemplo la nota hemerográfica titulada "No se dan abasto. Superan dengue y chikungunya al personal médico", Diario de Yucatán, 1 de septiembre de 2015.
} 
curativas y de prevención que cumple, lo caracterizan también sus funciones socioeconómicas dentro de los grupos en los que opera, pues en muchos casos es el único medio con el que cuenta la población. Sus caracteres básicos son: eficacia pragmática, centralidad de la experiencia como herramienta para establecer diagnósticos y emprender acciones, concepción de la salud como bien de uso, participación simétrica y homogenizadora, legitimidad grupal y comunal, apropiación de prácticas originadas en otros modelos, tendencia sintetizadora (Menéndez, 1992: 105-106). La autoatención así entendida, se identifica con lo que en la literatura de ciencias de la salud se denomina como "medicina doméstica", definida como el proceso dinámico por el cual las unidades domésticas combinan conocimiento interno (recursos, normas de comportamiento y patrones) con elementos externos (servicios, productos, información y habilidades) para restaurar, mantener y promover la salud de sus miembros (Berman y Bhattacharyya, 1994: 205).

Aunque es cierto que en la realidad interactúan diferentes modelos de atención, prevalece a nivel global el modelo biomédico tanto en términos económicos, como políticos, ideológicos y legales. Su hegemonía le viene, por un lado, de ser la forma de atención legitimada por el Estado, a la cual destina todos sus recursos económicos y jurídicos; y por el otro, de que subordina a otras prácticas respecto de las cuales resulta dominante. Las demás prácticas y representaciones existentes no quedan anuladas o erradicadas, aunque sí se modifican. Sin embargo, las tensiones que genera la hegemonía del modelo biomédico en su relación con otras formas de atención se advierten desde el punto de vista institucional o de los curadores, pues desde la perspectiva del enfermo y sus familias estas diferencias pueden formar parte del mismo proceso.

El ámbito de la salud a nivel poblacional se entiende como un proceso dinámico que se construye, desarrolla y transforma en un espacio-tiempo determinado, profundamente vinculado con la vida de un colectivo y con sus prácticas culturales y formas de percibir el mundo (proceso denominado salud/enfermedad/atención) (Sacchi et.al, 2007: 271; Menéndez, 1994: 71-72; Rosen, 2005:50). Estos procesos, al desarrollarse entre los grupos indígenas en México, muestran un fenómeno complejo al insertar, además, condiciones de pobreza y desigualdad. Frente a este panorama, los colectivos sociales acuden a diferentes "modelos, saberes y formas de atención y prevención de los padecimientos" con distintas técnicas diagnósticas y variados tratamientos y estrategias de curación (Menéndez, 2009: 25). Entre los grupos indígenas se ha analizado la presencia e interacción de los modelos tradicional y biomédico. Si bien la relación de la medicina tradicional y la alopatía registra tensiones, conflictos y antagonismos (Módena, 1990; Sesia, 1992; Freyermuth, 1993; Lerín, 2004: 113), esta aparente dicotomía es más compleja pues existen otras formas de atención escasamente reconocidas, como la "autoatención".

\section{Metodología}

Los tres ejes que articulan este artículo son modelos de atención, representaciones culturales y familia. La base empírica para explicar su interrelación se construyó a partir de registros etnográficos; los dos primeros se delimitaron a través de entrevistas abiertas y "carreras curativas", y el segundo mediante entrevistas cerradas que incluyeron las variables de organización socio-económica, producción y trabajo, alimentación, autoridad y vivienda.

Las entrevistas abiertas fueron realizadas durante los meses en los que se extendió la epidemia de fiebre chikungunya en la comunidad maya de San Pedro Juárez, municipio de Tizimín. Entre julio y diciembre del 2015, hicimos varias visitas a la localidad para realizar registros específicamente relacionados con la fiebre chikungunya. Mediante entrevistas abiertas, recogimos las "carreras curativas" de diez familias de la localidad. Las principales interlocutoras fueron las mujeres, madres de familia, quienes nos relataron sus experiencias por haber enfermado así como por haber cuidado y acompañado a sus familiares que 
también padecieron la fiebre. Estas historias fueron nutridas por la intervención, durante las entrevistas, de otros miembros del grupo familiar: esposos, hijos/as, abuelos/as, quienes añadían información u opiniones al discurso central elaborado por las mujeres. Consideramos importante referir que nosotros también enfermamos de fiebre chikungunya; en retrospectiva pudimos ver que, más allá de lo anecdótico, este hecho que estuvo completamente fuera de nuestras manos imprimió una dinámica particular a las entrevistas; permitió la construcción de un espacio de identificación entre entrevistadores y entrevistados que se acerca a lo que en la antropología conocemos como "observación participante", y en el que nosotros aportamos compartiendo nuestra propia experiencia.

También entrevistamos al personal de salud que atiende en la localidad: el médico de la Caravana de Salud y la promotora de salud local; ello nos permitió tener una aproximación a nivel comunitario sobre la irrupción de la epidemia y las acciones emprendidas por los afectados para recibir atención, más allá de los testimonios circunscritos al ámbito familiar.

La identificación de las familias entrevistadas obedeció a criterios surgidos de un proyecto más amplio sobre la relación entre alimentación y salud en esa misma localidad. Se trata de una investigación cualitativa trabajada a partir del análisis de 10 estudios de caso en los que se relacionan las variables de organización socio-económica, salud/enfermedad/ atención y alimentación. Esto significa que la selección de informantes para la elaboración de este artículo precedió a la irrupción de la epidemia de fiebre chikungunya en el 2015. Desde el 2014 realizamos varias visitas a San Pedro Juárez para seleccionar a las 10 familias que trabajaríamos como "estudios de caso", estableciendo como criterios necesarios: que al menos alguno de sus miembros hablara la lengua maya; que al menos uno de sus miembros realizara trabajo agrícola; que al menos uno de sus miembros estuviera en edad escolar. No fue difícil hacer la selección, pues al menos los dos primeros criterios elegidos son compartidos por la mayoría de las familias en San Pedro Juárez.

Habiendo seleccionado las familias, para el proyecto amplio que hemos referido, se les aplicaron tres tipos de instrumentos: una entrevista cerrada para obtener información etnográfica (organización social, medios de vida, producción, vivienda, religión); otra para recoger información sobre salud y alimentación; y una entrevista abierta que recabar "carreras curativas" sobre muy diferentes padecimientos (diabetes, mordeduras de serpiente, luxaciones, tuberculosis, y otros padecimientos culturalmente delimitados como "susto").

Para la aplicación del primer y tercer instrumento, contamos con la participación de antropólogos que acudieron a la localidad, se hospedaron ahí, convivieron con la gente, observaron directamente la información que fueron documentando en los instrumentos etnográficos. La aplicación del segundo instrumento se hizo a las mismas familias, y fue realizada por dos nutriólogas que recopilaron datos biométricos de los integrantes de las unidades domésticas e historias dietéticas.

Cuando ocurrió el primer brote de fiebre chikungunya en el estado de Yucatán, nosotros nos encontrábamos haciendo este trabajo, y entendiendo la importancia del fenómeno del cual estábamos siendo testigos, nos dimos a la tarea de enfocar nuestros esfuerzos y recursos en documentar la irrupción de este problema de salud pública.

Decidimos tomar como base a las 10 familias que ya habíamos seleccionado, y de las cuales ya teníamos información etnográfica para delimitar los grupos y comprender su dinámica interna; empleamos la misma herramienta de "carreras curativas" para abordar el caso específico de la fiebre chikungunya. Estas entrevistas las realizamos nosotros personalmente, e incluso un año después (2016) nos dimos a la tarea de filmar algunas de ellas para la elaboración de un reportaje multimedia. ${ }^{4}$

La "carrera curativa" permite capturar la sucesión encadenada de hechos prácticos puestos en marcha para encarar la enfermedad. Estas estrategias buscan la curación o el alivio

4 http://mosquitoyuc.wixsite.com/pmosquitoyucatan 
parcial de la enfermedad, utilizando diversas estructuras de atención que no necesariamente son excluyentes, sino que reflejan la combinación de unas y otras (biomedicina, medicina tradicional, autoatención). La "carrera" inicia desde la detección de algún malestar y de la evaluación inicial de su severidad por parte de los propios sujetos o sus familiares más cercanos. A partir de ahí, se prosigue con el relato de la evolución del malestar, de las desiciones tomadas para la búsqueda de atención, de la intervención de distintos sujetos dentro de la propia familia o externos, y el conjunto de la experiencia reconstruida en torno al proceso de enfermedad/atención. Una de las características de las "carreras curativas" es que inician la identificación y análisis de las formas de atención desde los sujetos y grupos sociales, y no a partir de los curadores. Ello nos permite acercarnos a las formas de atención que intervienen en un contexto determinado y observarlas articuladamente (Kleinman, 1988: 4; Osorio, 2001: 39-40; Menéndez, 2009: 21).

Pero al externar los hechos, los sujetos reconstruyen también sus percepciones, explicaciones, evaluaciones y opiniones; atribuyen significados a su experiencia y la sitúan en su propio marco cultural y formas de percibir el mundo. De esta forma, las entrevistas abiertas nos permitieron mirar más allá de hechos concretos, y abordar también las representaciones culturales. La verbalización de la experiencia en torno a la enfermedad y la búsqueda de atención, que aquí llamamos "carreras curativas", construye un discurso en el que es posible identificar las huellas de las representaciones culturales. Sin embargo, ello entraña la dificultad de dar voz a los actores sociales y diferenciarla, en nuestro discurso escrito, del análisis del investigador. Para dar cuenta de estas diferencias, hemos elegido hablar en primera persona del plural cuando de nuestras propias ideas y explicaciones se trata, y en tercera persona para exponer las formas y contenidos de la experiencia y la construcción colectiva en torno a la enfermedad. Esta decisión, asimismo, nos ha permitido respetar el anonimato de las personas que aceptaron colaborar con nosotros en esta investigación.

La decisión metodológica de tomar como unidad de análisis a las familias, obedece a la centralidad que ocupa la autoatención en el campo de la salud a nivel local, y a los vacíos que ha dejado tanto la medicina coporativa pública como la medicina tradicional, documentados previamente en nuestro proyecto. Sin embargo, la delimitación de estas familias representó un reto, y su definición conceptual previa al trabajo de campo no fue posible mediante un marco de referencia teórico específico, precisamente porque sus fronteras, funciones, dinámica y procesos de identificación son móviles. De acuerdo con los datos censales disponibles, en San Pedro habita un total de 63 familias, compuestas por una pareja, o un jefe/jefa de familia, y sus hijos solteros (familia nuclear). Sobre esta base, el estado distribuye recursos y programas. Sin embargo, en la realidad una o varias de estas unidades funcionan como un solo grupo. La literatura antropológica especializada en el tema, identifica como criterios para la definición de familia: su naturaleza coporativa (principalmente por el uso y tenencia de la tierra y las fuentes de agua), el parentesco como una forma de construir relaciones sociales, el reconocimiento de una autoridad, la residencia común, la transmisión del patrimonio material y simbólico, la socialización primaria, el cuidado de enfermos y ancianos, la producción y el consumo de alimentos y otras tareas cotidianas necesarias para la reproducción física y social (Bender, 1976; Yanagisako, 1979; Segalen, 1981; Robichaux, 2007). Sin embargo, de acuerdo con Hareven (1974: 329), el fenómeno familiar es un proceso y no una cosa; los grupos sociales así constituidos se transforman y adaptan a contextos específicos, tanto de su entorno inmediato como otros más amplios. Nuestra delimitación de los grupos sociales que aquí llamamos familia, por lo tanto, se basó en los registros etnográficos que realizamos antes de la irrupción de la epidemia de fiebre chikungunya en San Pedro Juárez. En términos generales, caracterizamos a las familias como un grupo cuyos rasgos principales son: 
Que tienen como referente inmediato al parentesco por filiación y por alianza. Por filiación destacan los vínculos patrilineales

Que comparte un espacio de residencia común (el "solar" o terreno) en el que se asientan las viviendas de una o más familias nucleares, generalmente vinculadas virilocalmente. Este es también un espacio de producción para cultivos de traspatio y cria de animales.

Que comparte la tierra (solar, milpa o parcela) para la producción de alimentos; pero que diversifican sus ingresos gracias al trabajo individual de sus miembros. Que reconocen una autoridad femenina al interior, que se expresa en las actividades domésticas.

Que comparten la obligación en torno al cuidado de menores, ancianos y enfermos.

Que consiguen, preparan y consumen los alimentos de manera colectiva, en torno a un "fogón común".

\section{La epidemia a nivel local. Entorno comunitario, familiar y patrón de contagio}

San Pedro Juárez es una ranchería perteneciente al municipio de Tizimín, ubicado al oriente del Estado de Yucatán. ${ }^{5}$ Según los conteos del Instituto Nacional de Estadística y Geografía (INEGI, 2010), la localidad tiene una población total de 268 individuos, distribuidos en 63 hogares censales e igual número de viviendas. El 56\% de la población es bilingüe, hablantes de maya y español, mientras que el 95\% habita en hogares censales considerados indígenas. Tan sólo por el criterio lingüístico, podemos considerar a esta localidad como predominantemente maya, a lo que podríamos sumar muchos otros indicadores de identidad que reforzarían esta observación, como la práctica de rituales agrícolas de tradición maya, el sistema familiar de tipo mesoamericano, la auto-identificación, entre otros.

El grado de marginación de San Pedro, según el Consejo Nacional de Población (CONAPO, 2010), es "alto": cerca del 30\% de la población mayor de 8 años es analfabeta, el grado promedio de escolaridad es de 5 años (primaria incompleta), y en algunos hogares persiste una falta de acceso a servicios básicos como agua entubada, luz eléctrica o drenaje. ${ }^{6}$

Si bien desde julio de 2015 la Secretaría de Salud Estatal declaró como zona de riesgo el municipio de Tizimín, por ser de los primeros en presentar casos de la enfermedad (junto a Valladolid y Tinum), al mismo tiempo el Centro de Salud Local contradecía las declaraciones oficiales, negando haber registrado algún caso positivo. ${ }^{7}$ Ya en agosto, las áreas de urgencias del Hospital General de San Carlos y de consulta externa del Centro de Salud de Tizimín estaban repletas de personas con cuadros febriles por encima de los $38.5^{\circ}$, erupciones rojas en la piel, fuertes dolores de cabeza y en articulaciones. ${ }^{8}$ De manera anónima, personal del salud del municipio aseguró a la prensa que entre instituciones sociales y médicos particulares se habían atendido en la cabecera cerca de 10,000 casos con la sintomatología

\footnotetext{
5 Para viajar de la ranchería de San Pedro a su cabecera municipal (Tizimín) en transporte público, se requieren entre hora y media y dos horas.

$6 \mathrm{Si}$ bien es cierto que la epidemia se extendió por todo el estado, los pobres fueron los más vulnerables al contagio. Asociación nada nueva. Farmer (2001: 4-5) reconoce la existencia de una antropogénesis o una sociogénesis en las llamadas enfermedades infecciosas emergentes; el grupo con mayores probabilidades de padecerlas se define más por su condición socioeconómica que por la latitud de las tierras que habitan.

7 Diario de Yucatán, 15 de julio de 2015, y 16 de julio de 2015.

8 Notirasa, 1 de agosto de 2015. Farmer (2001: 3) opina que una de las ventajas de las enfermedades emergentes es el sentido de urgencia que despiertan en la burocracia; sin embargo, lo que se pudo observar durante el 2015 en Yucatán fue falta de organización y articulación entre distintos niveles e instancias de gobierno (SSA -federal y estatal-, gobiernos municipales y gobierno estatal), además de indolencia y elaborados y audaces intentos oficiales por maquillar cifras y negar realidades.
} 


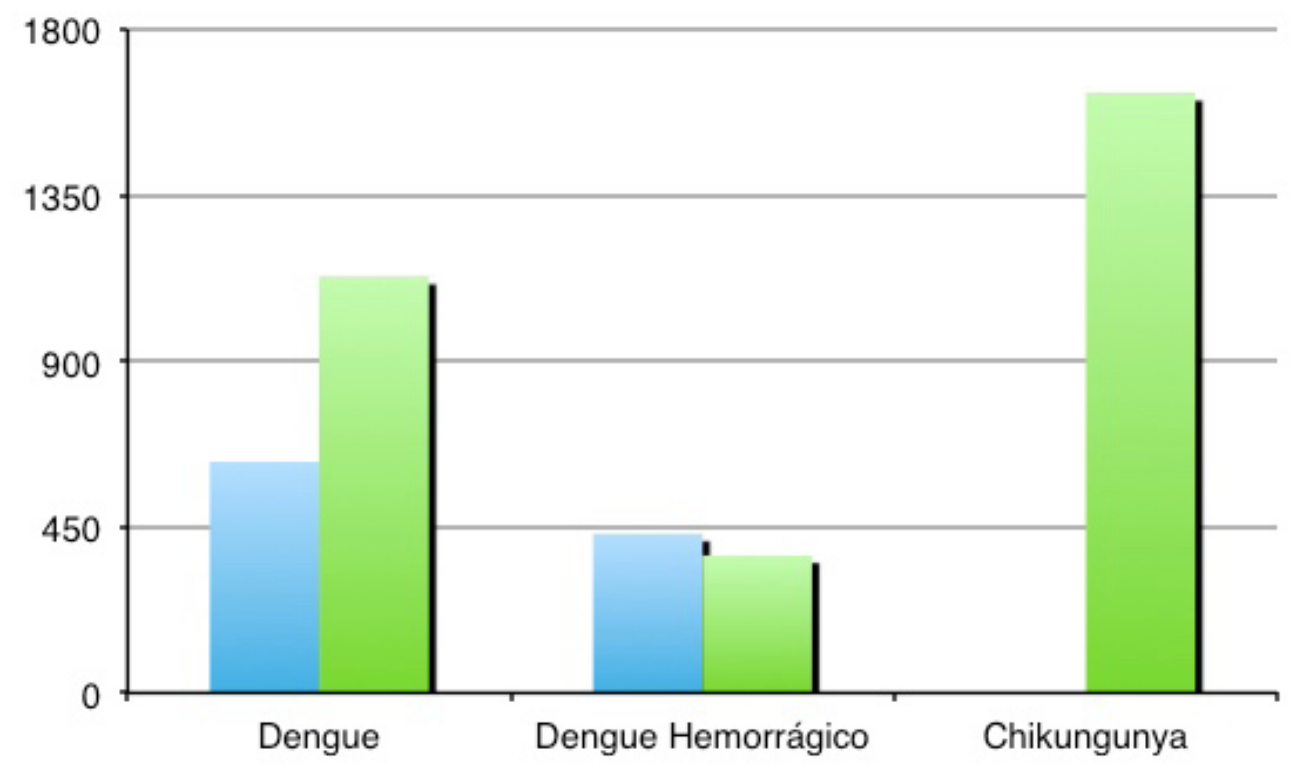

Gráfica 1. Totales de casos confirmados por la Secretaría de Salud de enfermedades transmitidas por el vector del mosco Aedes aegypti en Yucatán, 2014-2015

Elaboración propia con base en: Boletín Epidemiológico, Sistema Nacional de Vigilancia Epidemiológica, Sistema Único de Información, Boletín semana 52 (acumulado), 2015.

de la fiebre chikungunya. Ya en octubre, la extensión de la epidemia en todo el municipio y sus localidades era innegalbe. ${ }^{9}$

Es importante referir que no se cuenta con datos precisos que permitan calcular la prevalencia de la fiebre chikungunya durante el 2015, ni para esta localidad, ni para gran parte del estado. Este vacío de información lo podemos atribuir a diferentes factores que observamos tanto en la ciudad de Mérida como en la localidad de San Pedro: 1) no todas las personas que se sintieron afectadas con los síntomas y signos característicos de esta enfermedad, recibieron atención médica especializada, 2) únicamente el sector público de la atención médica hace este tipo de registros, 3) aún habiendo acudido a recibir atención médica en el sector público, los diagnósticos se hacían mediante signos y sintomas, y muy pocos con análisis de laboratorio (de hecho hubo escasez de reactivos para estos análisis, aún en el sector privado), 4) sin un resultado de laboratorio que lo constatara, los médicos de manera oral daban a los pacientes un diagnóstico de fiebre chikungunya, pero no lo registraban como tal sino llanamente como "fiebre", 5) el diagnóstico basado únicamente con base en síntomas y signos es aleatorio, dada la similitud que existe entre la fiebre chikungunya, el zika y el dengue. En todo caso, estimar la prevalencia rebasa los objetivos de este artículo, pero sí debemos subrayar que en todas las familias entrevistadas hubo más de una persona que padeció entre julio y diciembre del 2015 los síntomas que caracterizan a la fiebre chikungunya, y algunos de ellos fueron diagnosticados por algún médico, del sector público o privado, con base en signos y síntomas, y ninguno a través de un estudio de laboratorio. En la gráfica 1 se muestran los datos oficiales con los que se cuenta sobre casos registrados a nivel estatal.

En San Pedro Juárez, por el mes de julio, se empezaron a registrar casos de personas que presentaban una sintomatología que, en un principio y ante la falta de información, los 


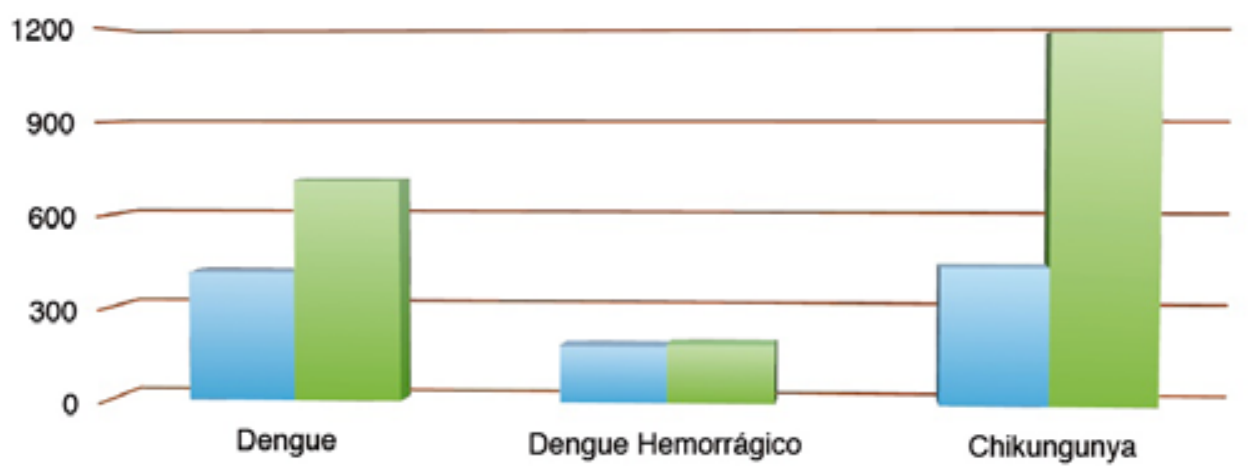

Gráfica 2. Totales divididos por sexo del número de casos confirmados por la Secretaría de Salud de enfermedades transmitidas por el vector del mosco Aedes Aegypti en Yucatán, 2015 Elaboración propia con base en: Boletín Epidemiológico, Sistema Nacional de Vigilancia Epidemiológica, Sistema Único de Información, Boletín semana 52 (acumulado), 2015.

afectados, sus familiares y el personal de salud, atribuyeron al dengue -dada su experiencia previa con esta enfermedad; aunque reconociendo que los dolores en articulaciones eran mucho más agudos y las erupciones en la piel atípicas. La información que comenzó a circular en televisión y radio, seguida de las primeras visitas al médico en la cabecera municipal y los diagnósticos del personal de Salud que acude a la localidad una vez por quincena, pronto desterraron la idea de que se trataba de dengue para afirmar de que en realidad era fiebre chikungunya.

Las entrevistas realizadas coincidieron en el reconocimiento de un patrón de difusión de la enfermedad a nivel local, identificando claramente el orden de los sectores de la localidad que fueron presentando los síntomas: así, por atrás de la iglesia, primero la familia tal, luego sus vecinos, después las familias que están por la escuela, seguidas por las que viven cerca del molino, las del cabo del pueblo, y de ahí, a todo el pueblo.

$\mathrm{Si}$ bien registramos familias enteras que fueron contagiadas, tanto los hombres como las mujeres entrevistadas externaron la idea de que la fiebre chikungunya no a todos afecta igual, sino que las más vulnerables tanto al contagio como a las fiebres más altas y al dolor de articulaciones, crónico e incapacitante, habrían sido las mujeres, las amas de casa. Esta vulnerabilidad fue atribuida a la condición física de unos y otras ya que, según se afirmó, el trabajo diario en la milpa fortalece el cuerpo de los varones, haciéndolos más resistentes al dolor y al abatimiento; mientras que nos explicaron que la natural tendencia de los niños a hacer ejercicio todo el día mediante el juego, los volvería tenaces frente a esta enfermedad en específico. Según esta visión, las mujeres amas de casa no tendrían esta fortaleza y serían por ello más propensas a la postración. Sin embargo, nuestra propia observación en campo nos mostró que ellas se levantan al alba a acarrear agua, alimentar los animales y cuidar los cultivos del traspatio, desyerbarlo, limpiar la casa, lavar los trastes, cargar cubetas repletas de maíz para llevarlas al molino, tortear, lavar la ropa (emplean entre dos y tres horas en esta tarea), cocinar, servir de comer, cuidar de los mayores y otras tantas tareas de su rutina cotidiana que, hasta que se pone el sol, exigen esfuerzo físico. No obstante, la percepción generalizada en la localidad, tanto por parte de los hombres como de las mujeres mismas, es que ellas no tienen igual fortaleza, y a ello adjudican que el contagio y dolor articular sea más fuerte y persistente en ellas. ${ }^{10}$ Los datos oficiales coinciden con esa observación empí-

10 La medicina ha establecido que la artritis reumatoide es un padecimiento más común entre mujeres que entre hombres, con una proporción de 3 a 1, Scott y Huizinga, 2010. 


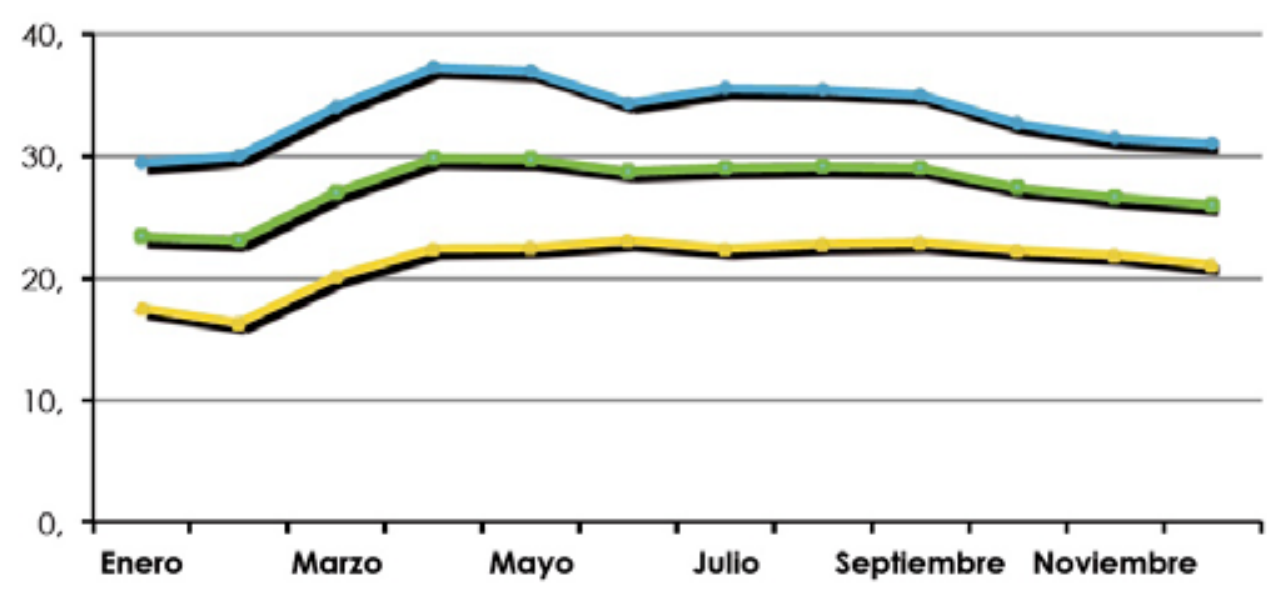

Gráfica 3. Temperaturas medias registradas en 2015 en Yucatán

Elaboración propia con base en: Sistema Meteorológico Nacional, http://smn.cna.gob.mxBoletín Epidemiológico, Sistema Nacional de Vigilancia Epidemiológica, Sistema Único de Información, Boletín semana 01-52, 2015.

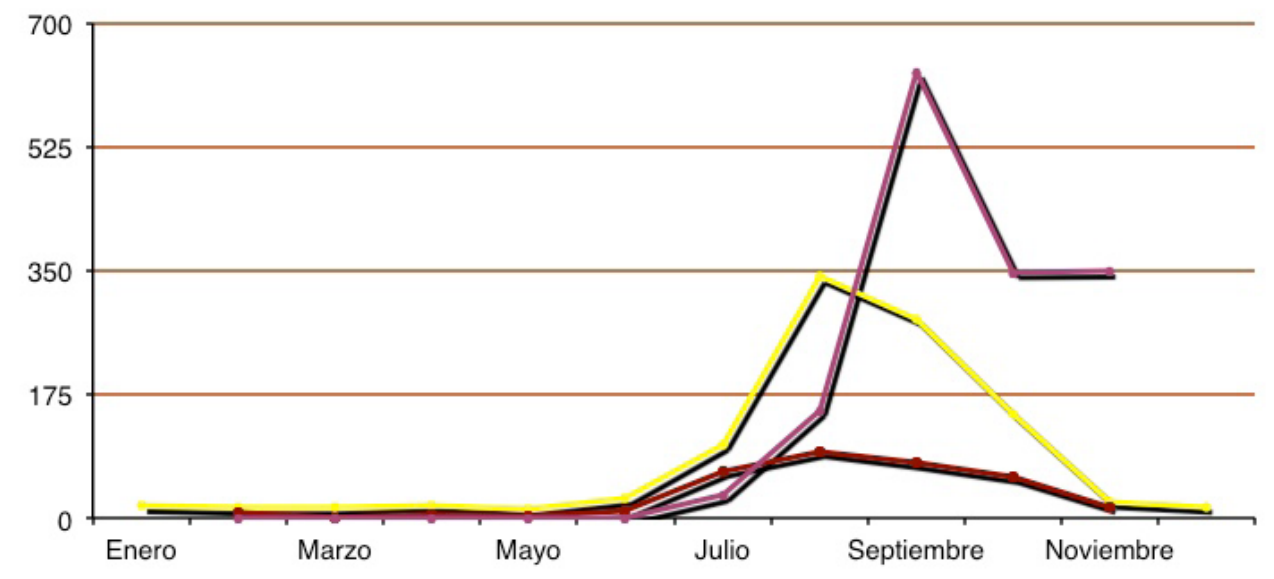

Gráfica 4. Casos confirmados por la Secretaría de Salud de enfermedades transmitidas por el vector del mosco Aedes aegypti en Yucatán, 2015

Elaboración propia con base en: Boletín Epidemiológico, Sistema Nacional de Vigilancia Epidemiológica, Sistema Único de Información, Boletín semana 01-52, 2015.

rica respecto al contagio diferencial, el cual se advierte no sólo en torno a la enfermedad de Chikungunya, sino también a la de Dengue (ver gráfica 2).

Además del argumento respecto a la fuerza corporal, el contagio diferencial en cuanto a sexo también se atribuyó a que los hombres pasan la mayor parte del día fuera del poblado, estando menos expuestos a la picadura de los "moscos malos". En efecto, para cuidar de sus milpas los varones establecen campamentos temporales en el campo, donde pasan entre cuatro y cinco días de la semana si los terrenos se encuentran a distancia considerable, y si están más cercanos transcurren ahí por lo menos la mitad del día. ¿Qué sucede entonces? Por un lado, sobre el vector Aedes aegypti se sabe que tiene hábitos netamente antropófilos y domésticos, con radicación de criaderos en la vivienda o su peridomicilio (Salvatella, 1996: 2); ello significa que el vector se reproduce en los poblados y no en las milpas (donde 
hay muchos depredadores). Por otro lado, las campañas de prevención y erradicación del mosco transmisor tienen a la fumigación como una de sus principales estrategias, pero al fumigar no sólo se matan mosquitos, sino toda una serie de insectos que forman parte de procesos de polinización que acaban por quebrar la cadena trófica animal (Spinelli, 2016). En los montes, en las milpas, esa cadena trófica se encontraría menos vulnerada, permitiendo a los predadores naturales de los moscos cumplir su papel. Se trata, entonces, de un evidente problema de salud pública.

Diciembre fue el mes en el que se identificaron los últimos casos de fiebre de chikungunya en la localidad, dato que coincide con lo registrado a nivel general en todo el estado de Yucatán. En efecto, existe una correlación entre la oviposición del Aedes aegypti (mosco transmisor de dengue, chikungunya y zika), altas temperaturas y precipitaciones abundantes, llevando a una mayor actividad del mosco a comienzos del verano e inicio del otoño, periodo de mayor riesgo epidemiológico (Stein et.al, 2005: 559) (ver gráficas 3 y 4).

\section{Modelos de atención y terapéutica}

Desde hace aproximadamente una década en San Pedro Juárez se ha registrado un desplazamiento de la Medicina Tradicional (curanderos y parteras) y del conocimiento de la herbolaria, tanto especializado como doméstico. Los modelos de atención que dominan en la localidad son el Modelo Biologicista, con notables vacíos en su implementación por parte del sector de salud pública junto a una exigua participación del sector privado, y el Modelo de Auto-atención fincado a partir de las familias.

Este desplazamiento, sin embargo, ha sido paulatino y comenzó hace aproximadamente 30 años, a partir de 1974 con la puesta en marcha a nivel nacional del Programa de Parteras Empíricas, llevando a la partera empírica tradicional a un proceso de "subordinación ideológica" (Menéndez, 1992: 104). Otro de los procesos que ha incidido en el dominio del modelo biologicista a nivel local es la implantación del programa Solidaridad en 1988 (vigente hasta nuestros días, pero revestido con distintos nombres), ${ }^{11}$ que precisamente ha utilizado a las parteras tradicionales como "promotoras de salud", que lo mismo atienden partos que distribuyen medicamentos alópatas no controlados que la Secretaría de Salud deja a su cuidado, o derivan a enfermos a clínicas de salud locales o municipales.

Tal ha sido el proceso de desplazamiento de la herbolaria y la medicina tradicional, que frente a la epidemia del virus de chikungunya padecida en 2015 no se registró en San Pedro la utilización de algún recurso propio de esta terapéutica. Hasta hace diez años, la medicina tradicional era una forma de atender varios padecimientos, principalmente del estómago (dolores, diarreas y vómitos), pero igualmente para bajar y/o controlar fiebres, aliviar dolores e hinchazones en diferentes partes del cuerpo, irritaciones en la piel, contrarrestar el veneno por mordedura de serpiente y para atender padecimientos de filiación cultural como mal de ojo, malos vientos, susto, etc. Los habitantes de San Pedro Juárez acudían a un curador especializado en el mismo pueblo que preparaba remedios a base de plantas, y también visitaban a otros que vivían en los pueblos vecinos de San Luis y Tixcancal que además se especializaban en "sobadas". ${ }^{12}$

Pero los recursos de la herbolaria se usaban asimismo como una forma de medicina doméstica sin la intermediación de un especialista; las madres y abuelas empleaban estos saberes para atender a sus hijos y nietos, hoy padres y madres de menores en edad preescolar y escolar. Actualmente no se aplican más esos recursos terapéuticos, ni en el ámbito

11 Solidaridad (1988-2002), Progresa (2002-2007), Oportunidades (2007-2014) y finalmente Prospera (2014 a la fecha).

12 La "sobada" es un masaje terapéutico particular realizado por algunos curadores mayas (especialmente las parteras) con el fin de reposicionar un órgano o partes del cuerpo consideradas momentáneamente fuera de lugar. Quattrocchi, 2005. 


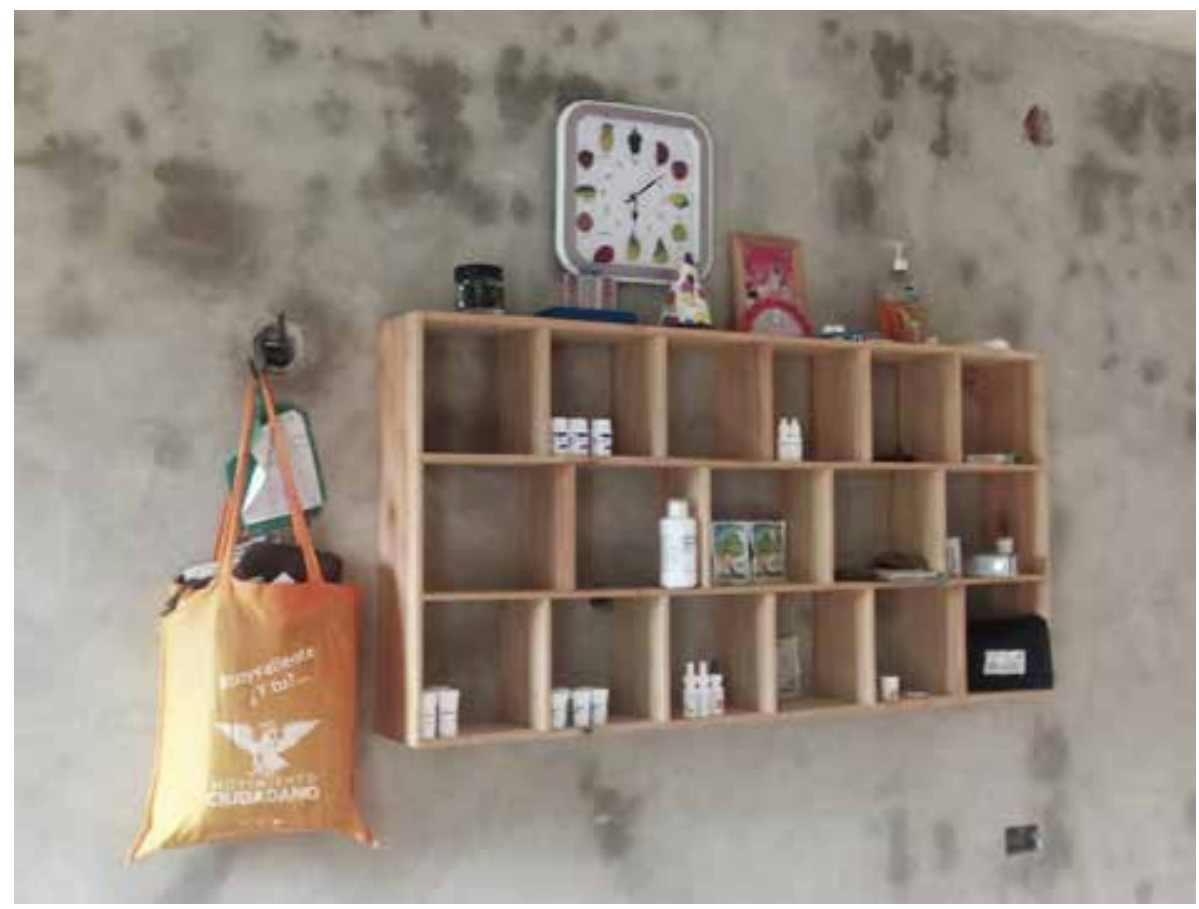

Foto 1: Dispensario en casa de la partera y "promotora de salud" local, ubicado en San Pedro Juárez, 2015. Obsérvese la escasa cantidad de medicamentos disponibles para la comunidad.

(Fuente: Fotografía del autor)

especializado ni en el doméstico. Pero en la memoria de su infancia queda que para bajar la temperatura corporal se usaba cebo de venado mezclado con café, untado en los pies; achiote (Bixa orellana) también preparado como cataplasma o sus hojas frotadas en el cuerpo; sábila (Aloe vera); hojas de anona (Annona reticulata) amarradas al cuerpo. Para combatir el vómito se preparaban infusiones de menta (Mentha spicata), toronjil (Melissa officinalis), hojas de naranja, hojas de chaya (Cnidoscolus aconitifolius) y sábila. Para la hinchazón de pie se utilizaba ruda "sancochada" 13 de la que se preparaba un cataplasma. Hojas del árbol de aguacate (Persea americana) para el dolor de piernas; artemisa (o altamisa) para la irritación de la piel, entre otros remedios.

Estos saberes relativos al uso de la herbolaria con fines curativos, eran reproducidos al interior de las familias y transmitidos de una generación a otra a través de líneas de filiación femeninas (abuelas, madres, hijas). A partir de las entrevistas realizadas advertimos que, al interior de las familias, los saberes curativos de las mujeres han registrado un gradual desplazamiento, del uso de plantas hacia el consumo de fármacos de laboratorio. Nuestra propia observación etnográfica, nos permite plantear la posibilidad de que este fenómeno se explicaría, en parte, por la confianza y legitimidad social con la que cuenta la promotora de salud, quien articula la atención que se da al interior de las familias con la del sector público, e incluso incide en cierto grado en sus desiciones. Esta promotora es originaria y residente de la localidad, y dado su interés personal en el campo de la salud, por más de 20 años ha recibido instrucción por parte de la Secretaría de Salud y otras instancias oficiales, y sus conocimientos adquiridos en el campo de la biomedicina y el uso de fármacos orientan su labor con las familias que piden su ayuda y consejo. De hecho, este conocimiento alimenta

13 "Sancochar": cocer un alimento en agua, RAE. 
de manera importante la legitimidad y confianza con la que cuenta al interior de la localidad.

Dada la intervención que han tenido los gobiernos estatal y federal a través de distintos programas como Seguro Popular o el Programa Prospera, actualmente el 100\% de la población de San Pedro Juárez cuenta con acceso a servicios médicos públicos. De esta localidad, el Seguro Popular tiene 203 afiliaciones (75.7\% del total de la población), y el Instituto Mexicano del Seguro Social (IMSS) 9; pero dado que el 100\% de las familias están en el padrón de beneficiarios del programa Prospera, todos tienen acceso quincenal a la " $\mathrm{Ca}$ ravana de Salud". ${ }^{14}$ Este programa se plantea como objetivo explícito incrementar los niveles de inclusión y desarrollo social para la población en condiciones de pobreza y pobreza extrema, y de ahí que una de sus formas de operar sea articular la oferta institucional de programas de gobierno, principalmente de la Secretaría de Desarrollo Social (SEDESOL), la Secretaría de Educación Pública (SEP) y la Secretaría de Salud (SSA).

En el rubro de salud de este programa, precisamente con el apoyo no remunerado de la promotora de salud, se lleva un seguimiento de los principales padecimientos como diabetes, enfermedades respiratorias o gastrointestinales, anemia y desnutrición. A solicitud expresa, ella visita a las familias para atender básicamente enfermedades estomacales o respiratorias y está facultada para administrar los medicamentos con los que cuenta en el dispensario (ver tabla 1). Sin embargo, la periodicidad y la cantidad con la que estos medicamentos son surtidos es variable y a menudo insuficiente.

Tabla 1. Medicamentos administrados por la promotora de salud local (y partera)

\begin{tabular}{l|l} 
Medicamento & Terapéutica \\
\hline Ácido acetilsalicílico & Dolor y fiebre \\
\hline Acetaminofen (paracetamol) & Dolor y fiebre \\
\hline Aluminio y magnesio & Padecimientos del estómago \\
\hline Pasta Lassar & Irritaciones de la piel \\
\hline Benzoato de Bencilo & Infecciones de la piel (sarna) \\
\hline Albendazol & Parásitos estomacales \\
\hline Fumarato Ferroso & Anemia \\
\hline Dextrometorfan & Gripe y tos \\
\hline Cloranfenicol oftálmico & Infecciones de los ojos (conjuntivitis) \\
\hline Clorfeniramina & Resfriado, alergias (antihistamínico) \\
\hline Electrolitos orales & Deshidratación \\
\hline Miconasol crema & Micosis en la piel
\end{tabular}

Fuente: elaboración propia a partir de datos etnográficos

Como ya se adelantó, la Secretaría de Salud hace llegar a la localidad cada 15 días una unidad médica itinerante conocida como la "Caravana de la Salud", atendida por un médico y un enfermero. Además de atender a pacientes por distintas dolencias y/o padecimientos, tienen a su cargo el programa de vacunación y promoción de la salud (prevención). De manera que la promotora de salud funciona como una intermediaria entre estas caravanas y los habitantes locales, pues es al médico de esta unidad al que responde, y es él quien le da instrucciones sobre las acciones a llevar a cabo en su ausencia.

En el tope de esta cadena de atención institucionalizada, se encuentra el Hospital San Carlos en Tizimín, cabecera municipal, a donde son derivados los enfermos que requieran 
una mayor especialización que está fuera del alcance de la promotora de salud local o de la unidad médica de la caravana. No obstante, son generalizadas las opiniones sobre la mala atención que ahí se brinda y los excesivos tiempos de espera. Por ello, las familias que cuentan con los recursos necesarios optan por acudir, también en la cabecera municipal, a la medicina privada con el denominado Dr. Simi (consultorios adyacentes a farmacias). Se trata de una red nacional de farmacias de genéricos que surten medicamentos a precios considerablemente más bajos, y que además ofrecen consulta externa por \$35 (equivalente a 1.6 Dólares americanos).

Entre julio y diciembre de 2015, tanto la promotora de salud como los médicos en sus días de visita, atendieron a gran cantidad de personas cuyos síntomas eran cuadros febriles por arriba de $\operatorname{los} 38^{\circ} \mathrm{C}$, fuertes dolores en las articulaciones y erupciones en la piel. Muchas otras personas que también presentaron estos síntomas y signos no acudieron con ningún curador especializado. Frente a este padecimiento, las familias pusieron en marcha distintas prácticas para reestablecer la salud de sus integrantes:

1) Realizaron diagnósticos basándose en sus experiencias previas con el dengue. Este primer diagnóstico fue hecho por las madres de familia, independientemente si fueron ellas o sus familiares los primeros en enfermar. Cuando la información sobre el chikunguya comenzó a circular, los responsables de salud y las madres de familia no tuvieron dudas de que se trataba de esta última enfermedad. La mayor certeza vino de información dada por el sector salud y los medios de comunicación que destacaba que una de las diferencias más significativas entre el dengue y la fiebre chikungunya es la intensidad en los dolores de articulaciones, que pueden prolongarse hasta por tres años, y el salpullido en la piel.

2) Compartir prescripciones médicas y medicamentos entre los miembros de la familia. El dispensario local, a través de la promotora de salud, recibe al mes 70 "tiras" con 10 pastillas de paracetamol (acetaminofén) cada una. En un principio repartió una "tira" por enfermo (aunque hubiera varios enfermos en una familia), pero desde el mes de julio esto ya era insuficiente. Tan pronto se agotó, se echó mano del paracetamol en gotas que se tenía para los menores de edad, aunque fuera para atender a adultos. Éste tampoco duró mucho, y los enfermos (o sus familiares) se vieron en la necesidad de acudir a la cabecera municipal; algunos al Hospital San Carlos, otros al Dr. Simi, pero la mayoría sólo iba a tratar de conseguir éste medicamento directamente a las farmacias, por consejos de familiares y/o vecinos y prescindiendo de la evaluación y prescripción médica. Una caja de este medicamento costaba alrededor de \$35 mexicanos. Ya por el mes de agosto, se registró una escasez generalizada no sólo Tizimín, sino en todo el estado, ${ }^{15}$ así como en otras entidades del país en las que se registró la epidemia como Oaxaca, Sinaloa, Chiapas, Guerrero, Michoacán, Colima y Veracruz. ${ }^{16}$

Una entrevistada expresó que el paracetamol "se gastó como pan caliente", y recogimos varias historias de gente que aún con receta médica no lo conseguía. Esta situación generó mucho enojo. El testimonio de una señora, por ejemplo, relató que aun sintiéndose muy afectada viajó a la cabecera municipal para conseguir medicamentos para ella y sus hijos; aseguró que iba vomitando y con mucha calentura, que visitó todas las farmacias que pudo y no logró conseguir nada, ya en la última espetó al dependiente: "pa 'qué hijueputas tienen farmacia!, vallasen a la chingada!".

Frente a la extensión de la epidemia a nivel local y la escasez de paracetamol, la promotora de salud visitaba a las familias para ayudarles a bajar la fiebre de sus enfermos con paños mojados y baños de agua fría, especialmente cuando se trataba de niños o adultos mayores. Durante los meses siguientes, cuatro enfermos fueron canalizados al Hospital de

15 Diario de Yucatán, 19 de agosto de 2015.

16 Aristegui Noticias, "Hay más casos de chikungunya que los que reporta el gobierno: usuarios", 7 de agosto de 2015; La Jornada, sección Estados, 30 de julio de 2015. 
San Carlos por los dolores extremos e incapacitantes en las articulaciones, en donde fueron tratados con Dexametazona.

Buscando eludir lo que generalmente se juzga como una muy mala atención en el Hospital San Carlos, varias personas de San Pedro Juárez con la sintomatología de la fiebre chikungunya acudieron a los consultorios del "Dr. Simi" (consultorios adyacentes a farmacias) para recibir atención médica. Esta fue una opción a la que recurrieron no pocas familias. Y fue más una estrategia de auto-atención colectiva que individual, pues de una familia sólo acudía el primero en haber enfermado, y después con la misma receta se conseguían las medicinas y se seguían las indicaciones para el resto de los miembros del grupo familiar, según fueran enfermando. Por ejemplo, en una familia compuesta por padre, madre, abuela y dos hijas, primero enfermaron casi al mismo tiempo la hija menor y la abuela, la madre se hizo cargo de llevarlas a ambas al consultorio privado en la cabecera municipal; entre pasajes, consulta y medicinas, gastó \$400 (aproximadamente 23 Dólares americanos). Pocos días después cayeron enfermos los demás, y con la misma receta la señora viajó de nuevo para conseguir los medicamentos para su otra hija, su esposo y para ella misma. En otra familia, la madre enfermó primero y fue atendida por los médicos que acuden a la localidad quincenalmente; recibió una "tira" de Paracetamol (acetaminofén), pero como sus hijas enfermaron casi de inmediato, al día siguiente, cuando ya no estaban los médicos y en el dispensario local ya no había medicinas, las pastillas que había recibido se las dio a sus hijas y ella decidió tomar unas pastillas de Naproxeno que en otro momento el médico de la Caravana de Salud le había dado para el dolor de espalda.

De esta manera, la auto-atención fue una forma de cuidado que ocupó un lugar importante dentro del abanico de estrategias empleadas para enfrentar la fiebre de chikungunya en la localidad durante el 2015. Ésta se configuró mediante la auto-medicación y el cuidado en la alimentación. La primera estuvo orientada por los diagnósticos y prescripciones específicas que se hicieron a algunos enfermos (por la promotora de salud, el médico de la Caravana, en el Hospital San Carlos en Tizimín o en los consultorios adyacentes a farmacias), y que se extendieron al resto de la población siguiendo las rutas de las redes familiares. Se orientó también por las experiencias previas en torno al dengue (que sirvieron para los diagnósticos y la búsqueda de atención), y las experiencias en cuanto al uso de ciertos medicamentos para distintos padecimientos, como el caso del naproxeno antes referido, el uso de sueros para los vómitos o de ciertas pomadas para el dolor de articulaciones. Fueron las mujeres, madres de familia, quienes articularon esta distribución de prescripciones y medicamentos al interior de sus familias.

3) El cuidado de la alimentación. En cuanto a la alimentación, las mujeres también ocuparon un papel protagónico, no sólo porque cotidianamente ellas asumen el cuidado de los enfermos en sus familias, sino porque además recae en ellas la preparación de alimentos. Cuando ellas estuvieron imposibilitadas para preparar los alimentos, instruyeron a sus familiares más cercanos sobre cómo hacerlo: esposo e hijas principalmente; aunque también se registraron casos en los que las abuelas, aunque no vivieran próximas, apoyaban a las señoras llevando alimentos preparados cuando sus hijas caían enfermas. Para eliminar las náuseas que presentaron algunos de los enfermos, eligieron comida "ligera", como galletas saladas y tortillas. El médico de la localidad indicó a algunos enfermos que tomaran atole de avena, pero fue opinión común que para la gente de San Pedro Juárez es imposible dejar de comer tortillas de maíz; hacerlo -según algunas entrevistas- los debilitaría todavía más. Por otro lado, llama la atención que se considere que ciertas frutas, consumidas en el proceso de recuperación de alguna enfermedad, sea cual fuere, ayudan para reponer las energías perdidas: pera, manzana y plátano tabasco. Ninguna se cultiva localmente, por lo que deben ser compradas en la cabecera municipal y -a decir de la misma gente- son caras. Sin embargo, en muchos solares y patios de la localidad hay árboles de papaya (Carica papaya), matas de plátano manzano (otra especie de banana, muy pequeña), zapote (Pouteria sapota), naranja 
agria y otras frutas que no son consideradas óptimas para ser consumidas después de haber pasado por alguna enfermedad. Posiblemente estas ideas en cuanto a la alimentación de los enfermos están influidas por las diversas "pláticas" sobre nutrición que la Secretaría de Salud implementa a nivel local, pero que son diseñadas sin considerar a los recursos locales. Considero importante indagar más al respecto.

4) Cuidados mutuos. En cuanto a los cuidados a los enfermos, tomando como foco de observación a las familias, no es posible identificar a un miembro que categóricamente se haya hecho cargo del cuidado a los enfermos, puesto que fueron varios los contagiados. Madres, padres, hijos (hasta los menores de edad), abuelos -todos- en la medida de sus posibilidades, en algún momento de la epidemia, tuvieron que hacerse cargo del cuidado de alguien de su casa: conseguirles medicamentos, bajarles la fiebre, prepararles los alimentos, ayudarles a movilizarse, etc. Sin embargo, destaca la autoridad femenina al interior de las familias en varias fases del proceso de enfermedad/atención en torno a la fiebre chikungunya: fueron las primeras en hacer un diagnóstico, decidieron qué tipo de atención buscar (promotora de salud, sector público, sector privado) y para qué miembro de la familia (especialmente cuando la presentación de síntomas fue simultánea entre dos o más miembros de un grupo familiar); distribuyeron recetas y medicamentos disponibles, racionaron los recursos económicos del grupo para pagar atención y/o comprar medicamentos; evaluaron la eventual eficacia de los consejos de alimentación externos, hicieron ajustes entre éstos y sus propias prácticas alimentarias y dispusieron respecto a la dieta de los enfermos. Se debe subrayar, sin embargo, que esta autoridad no se puede atribuir a la coyuntura presentada por la emergencia de esta nueva enfermedad, sino que es un rasgo estructural de la dinámica familiar en la localidad y por lo tanto del modelo de auto-atención.

Para resumir, las principales estrategias familiares puestas en marcha para lidiar con el brote de chikungunya fueron: 1) diagnósticos basados en experiencias previas e incorporación de información nueva, 2) compartir prescripciones médicas y medicamentos entre los miembros de las familias, 3) cuidado en la alimentación, y distribución de tareas para la preparación de alimentos cuando la madre de familia caía enferma, 4) cuidados mutuos entre los miembros de las familias.

\section{Representaciones culturales}

Recabar testimonios, opiniones y experiencias durante el mismo año en que se presentó por primera vez la fiebre de chikungunya representó a nivel metodológico una interesante oportunidad para entender la manera en que una sociedad explica, da significado e incorpora la experiencia frente a nuevos padecimientos, así como el papel que juegan las instituciones y los medios de comunicación en este proceso; cómo los enfrenta de acuerdo con su proceso de salud/enfermedad/atención vigente, y la puesta en marcha de acciones de acuerdo con una organización social específica. Otra ventaja de haber registrado la situación en el momento en que se presentaba, es que permitió captar el problema antes de que el Estado y otros agentes (incluyendo investigadores, por ejemplo) robustecieran su injerencia en torno a él. ${ }^{17}$ Las "representaciones culturales" en torno a las enfermedades emergentes pueden ser consideradas como la "sustancia cognitiva" (conocimiento, imágenes, creencias, sentimientos y actitudes sobre una patología y el riesgo a contraerla) por la cual los individuos adquieren, almacenan e interpretan información relevante sobre las características de la enfermedad (Setbon y Raude, 2008: 493). ${ }^{18}$

17 Esta idea es de mi colega la Dra. Inés Cortés Campos, quien amablemente leyó una versión preliminar de este artículo y me señaló esta otra ventaja de haber registrado el fenómeno en el momento en el que se presentaba. 18 Estos autores realizaron un análisis, precisamente, sobre las representaciones en torno al chikungunya en su primera aparición en 2006 en las islas Reúnion y Mayotte (territorio ultramar de Francia), y encontraron una fuerte asociación entre las percepciones sobre el riesgo y características de la enfermedad y la vulnerabilidad 
En efecto, la fiebre de chikungunya es una enfermedad emergente, y ante su primera aparición en Yucatán en 2015 prevaleció la improvisación y la especulación, con algo -poco- de información entomológica y médica sobre el virus, su vector y la enfermedad. Esta información fluyó a cuentagotas y fue respaldada con la observación y experiencias previas vividas durante décadas con una enfermedad "prima"19 (dengue).

Las autoridades gubernamentales, por su parte, tendieron a minimizar la importancia de la extensión de la enfermedad; el 6 de septiembre de ese mismo año, por ejemplo, el Secretario de Salud estatal declaró en rueda de prensa que el incremento de consultas por enfermedades febriles se debía a que el chikungunya era un "padecimiento de moda", pero que en realidad no todos los casos se debían atribuir a esta enfermedad, evitando "sobredimensionar el tema ni llevar a una crisis nerviosa de alarma cuando realmente no la hay". ${ }^{20}$ Difícilmente se hubiera podido comprobar, dado que al igual que desde agosto hubo una escasez de paracetamol, la hubo también de reactivos para hacer los diagnósticos en laboratorio.

En medio de este contexto, en San Pedro Juárez, como en muchos otros lugares, surgieron muy distintas versiones, explicaciones e interpretaciones en torno a la etiología de esta enfermedad. Los entrevistados plantearon preguntas como: ¿Un mosco? ¿Una enfermedad de África? Pero ¿cómo? Si yo nunca he ido a África! O ¿qué, acaso vino ese mosco volando desde África a picarme? Debo subrayar que la gente tuvo que procesar esa información nueva en medio de la enfermedad, la falta de atención y medicamentos, y el dolor de articulaciones constante. Las que siguen, son algunas de las versiones recogidas en el campo (y sus variaciones), que muestran este dinamismo y complejidad mediante las cuales se configuran representaciones en torno a una enfermedad emergente:

1) Poco antes de que comenzara el contagio, pasaron volando a muy baja altura ciertos aviones muy extraños que a manera de fumigación tiraron la enfermedad en San Pedro Juárez; que los aviones eran de Estados Unidos (de los "gringos"); que lo que tiraron no fue la enfermedad sino los moscos malos. ${ }^{21}$ 2) Por culpa de todo el "alboroto" que están haciendo los maestros allá en la capital (se refieren a las marchas por los estudiantes desaparecidos de Ayotzinapa, Guerrero), eso provocó un aire malo, y los vientos lo llevaron hasta Yucatán, y ahí venía la enfermedad.

3) Los que enfermaron, antes de manifestar los síntomas de la enfermedad, llegaron a percibir un olor extraño.

4) Los terremotos echan gases a la atmósfera, y esos gases traen la enfermedad; por entonces había habido algunos de estos fenómenos en México.

5) El primer infectado fue un forastero originario de Monterrey (o del Distrito Federal o de Tizimín en otras versiones) y que secretamente llegó al pueblo; nadie lo vio directamente, pero fue por culpa de este forastero que enfermó todo el pueblo.

6) El mosco no es del pueblo; se enfermaron todos porque esos moscos vuelan mucho; el vector que transmite el virus del chikungunya es una mosca muy grande (tábanos). Incluso hubo quien afirmó haber observado cómo un tábano picaba a varias personas y que poco después cayeron todos enfermos.

asociada al padecimiento.

19 Así denominó el Dr. Carlos Machaín del departamento de arbovirología de la UADY, en una entrevista personal, a los virus de dengue, zika y chikungunya y a las enfermedades que transmiten.

20 Diario Por Esto!, 6 de agosto de 2015.

21 Esta versión fue relatada por diferentes personas. Con punto y coma “;” se añaden pequeñas variaciones sobre la misma. 
7) Es mentira que sea una enfermedad contagiosa, sólo a los más pobres les da porque no tienen defensas por la mala alimentación. La gente de San Pedro Juárez es muy pobre, y por eso enfermaron todos.

8) En realidad no es un mosquito el transmisor de este mal, sino que se trata de una enfermedad que "se escapó" de un laboratorio científico "gringo", donde fue creada.

Estas versiones, en apariencia distintas entre sí, presentan dimensiones compartidas: una de ellas es la idea de que el aire y los olores pueden ser transmisores de enfermedad y postración; independientemente de su origen (olor particular, emanaciones del subsuelo, "venenos" esparcidos intencionalmente, etc.) la atmósfera aparece como el medio por el cual un mal puede volverse colectivo. Esta explicación reviste la lógica muy antigua del planteamiento hipocrático respecto a las epidemias, según el cual los miasmas -al esparcirse y ser respirados por las personas o entrar en contacto con su piel- llevaban consigo enfermedad y muerte. La otra dimensión es la noción del riesgo encarnada en lo extraño, lo externo, como algo que exclusivamente llega de fuera. También está la pobreza, como una variable compañera de la vulnerabilidad ante las enfermedades.

\section{Consideraciones finales}

Este estudio de las prácticas implementadas para afrontar el primer brote de fiebre chikungunya en Yucatán (2015), tomó como unidad de observación a las familias, y a partir de sus experiencias se analizaron los modelos de atención preponderantes y su grado de articulación. A partir de este caso etnográfico, se documentó que en la localidad la hegemonía del modelo biomédico se presenta con los siguientes rasgos:

1) Reproducción de saberes y discursos biologicistas e individualistas por parte del personal de salud, las autoridades estatales y la información en los medios de comunicación: centrados en el virus, el vector, y en la no auto-medicación como paradigma de atención. Sin embargo, desde las familias se configuraron versiones y prácticas que cuestionaron esa hegemonía: se dudó de la información sobre el virus y el vector, se generaron versiones alternativas, y se recurrió -de manera sobresaliente- a la auto-medicación.

2) Omisión de la experiencia y la memoria histórica, también a nivel oficial (funcionarios, personal de salud y medios de comunicación). Se presentó a la fiebre chikungunya como una enfermedad completamente nueva, silenciando el hecho de que en Yucatán se tienen más de 300 años de experiencia con enfermedades víricas transmitidas por el vector aedes aegypti: entre 1648 y 1923 la fiebre amarilla fue endémica, y a partir de 1970 se convive también de manera endémica con el dengue. Sin embargo, precisamente la experiencia vivida por los sujetos y sus familias con el dengue, fue la base inicial con la que estos grupos diagnosticaron, tomaron desiciones, trataron y buscaron atención.

3) La terapéutica centrada en el uso de fármacos. El predominio de esta estrategia de tratamiento, propia de la medicina biologicista, se dio tanto desde los servicios de salud como desde la auto-atención emprendida por las familias; los primeros, sin embargo, insistieron en la no auto-medicación, por el contrario las familias constituyeron en ella su principal estrategia curativa. En este rasgo, se dio una transferencia de saberes entre el modelo biomédico y el modelo de auto-atención.

Así, fue posible observar que el principal modelo de atención que funcionó durante esta epidemia fue el de auto-atención, y su base fue la familia. Este modelo, sin embargo, no operó precisamente como una alternativa (práctica y/o ideológica) a la hegemonía del modelo biologicista, sino como un apéndice; como un complemento socio-económico (su- 
bordinado) necesario frente a las ausencias e insuficiencias del modelo médico corporativo público y privado. Los rasgos más evidentes de este modelo fueron:

1) Un diagnóstico llevado a cabo por los propios miembros del grupo familiar. Las bases para este diagnóstico se sentaron sobre la experiencia previa con el dengue; la información dada principalmente por los medios de comunicación y también (aunque desfasado) por personal de salud de la SSA; y la simultaneidad de síntomas y signos a nivel local. Sobre este último punto, si bien algunos diagnósticos "oficiales" los hizo el personal médico de la "Caravana de Salud" (del Estado de Yucatán), del Centro de Salud o médicos privados de la cabecera, estas experiencias se compartieron casi inmediatamente entre miembros del grupo familiar y vecinos, y sirvieron para diagnosticar a otros enfermos que no tuvieron contacto con algún profesional de salud. Vemos aquí otro punto de articulación entre el Modelo Médico Hegemónico y el de Autoatención. La eficacia pragmática de este último permitió a muchos evadir los tiempos de espera y/o los costos que suponen la atención pública y/o privada, convirtiéndose así en una alternativa curativa al tiempo que socioeconómica.

2) Al partir de un diagnóstico pronto, el grupo familiar actuó como el primer nivel real de atención. Para afrontar esta enfermedad, los grupos familiares se apropiaron rápidamente de las prácticas de la biomedicina, principalmente del uso de fármacos. La artrosis característica de la fiebre chikungunya y las dificultades de movilidad que trae consigo (en ocasiones prolongadas) condujeron a un mayor sentido de urgencia que supuso para la gente una necesidad imperiosa de fármacos que les permitieran continuar con su vida cotidiana.

En este caso, se propagó rápidamente la idea de que el consumo de Paracetamol (Acetaminofén) era la única y mejor salida frente al padecimiento. Convertido este consumo en paradigma terapéutico, la capacidad de la medicina pública para cubrir esta necesidad fue insuficiente, y pronto se acudió a la atención privada. El modelo privado ha extendido paulatinamente sus prácticas en áreas y sectores no urbanos por medio de los consultorios adyacentes a farmacias, lo cual ha conducido a un creciente uso de fármacos. Pero la centralidad del consumo de fármacos para atender la fiebre chikungunya, llevó a que incluso se prescindiera de la atención de un curador para tratar de conseguir directamente los medicamentos en farmacias. De esta manera, la auto-atención funcionó gracias a los "vacíos" que dejó el modelo corporativo público y privado, mostrando al Modelo Médico Hegemónico (biologicista) como dominante a nivel ideológico pero incapaz a nivel práctico. Sin embargo, las prácticas del modelo de auto-atención que aquí se han referido son rasgos estructurales del propio modelo, y no solo prácticas emergentes frente a la fiebre chikungunya. Son, asimismo, estrategias familiares para lidiar con los problemas que se registran en el Sistema de Salud de manera general.

El carácter "emergente" de la fiebre chikungunya se vivió en las percepciones y representaciones socioculturales sobre los orígenes, la etiología y la morbilidad de esta enfermedad. Como se refirió, la información por parte de las instituciones encargadas de la salud pública y de los propios medios de comunicación empezó a circular cuando ya la enfermedad se había enseñoreado en la localidad (y en gran parte del Estado de Yucatán). Fue apenas en septiembre cuando el médico que asiste cada quince días a la localidad dio una plática al respecto, y a la promotora de salud se le capacitó para dar más pláticas hasta el mes de octubre, cuando el contagio había ya comenzado desde julio de 2015. En los discursos recabados en campo, las representaciones en torno al padecimiento se construyeron a partir de experiencias previas sobre enfermedades parecidas, pero también con información del contexto local, estatal e incluso nacional, no sólo de salud, sino también política, económica y social, para construir explicaciones que revistieran cierta lógica de acuerdo con su propio marco de percepción cultural. Sobre el entorno local destacan explicaciones relacionadas con la pobreza y la vulnerabilidad, sobre los contextos estatal y nacional, las variables so- 
ciopolíticas que influyen en la generación y reproducción de los nuevos padecimientos, y en general en las concepciones sobre las epidemias se identifican huellas del pasado más remoto sobre los miasmas como productores de enfermedades. Y así, pues, a partir de las reflexiones elaboradas en torno a la enfermedad, los entrevistados construyeron discursos alternativos al hegemónico:

- Cuestionaron el paradigma de la transmisión vectorial

- Desnaturalizaron a los mosquitos; se les personalizó como "malos"; o se les hizo pieza clave de un complot.

- Destacaron aspectos socio-económicos de la vulnerabilidad, omitiendo la concepción individualista respecto a la enfermedad.

- Se apropiaron de saberes en cuanto al uso de fármacos, y las prescripciones médicas -originalmente individuales- se socializaron. Esta apropiación llevó a los enfermos y sus familias a extender su reclamo al mercado de consumo por no abastecer eficazmente, además de las quejas cotidianas que se circunscriben al ámbito público de los servicios de salud.

\section{Agradecimientos}

La investigación para la elaboración de este artículo se llevó a cabo en el marco de un proyectos de investigación titulado "Análisis de los Sistemas Locales de Salud en comunidades mayas del Oriente de Yucatán, México: alimentación, enfermedad, prácticas e ideas" (Id. 407) financiado por el Consejo Nacional de Ciencia y Teconología, México (CONACyT), en la convocatoria "Fronteras de la Ciencia" (2016-2018) y es coordinado por la Dra. Paola Peniche Moreno; algunos testimonios recabados para este artículo fueron parte del material que se videograbó para la realización de un reportaje multimedia elaborado en el marco del proyecto Enfermedades transmitidas por el Aedes aegipty: dengue, zika y chikungunya en Yucatán, (CONACyT 269803) de la Convocatoria de Apoyo a Proyectos de Comunicación Pública de la Ciencia, la Tecnología y la Innovación 2016 del Consejo Nacional de Ciencia y Tecnología, bajo la responsabilidad del Dr. Gabriel Angelotti Pasteur. Ambos proyectos se realizan en colaboración entre el Centro de Investigaciones y Estudios Superiores en Antropología Social (CIESAS) y la Universidad Autónoma de Yucatán (UADY). En la recopilación de datos participaron los autores de este artículo, y los becarios de nivel licenciatura del proyecto amplio Br. Yessenia Estefanía Castillo Puc y el Br. Sergio Novelo Barco. La participación y ayuda de la promotora de salud local, cuyo nombre omito por cuestiones de confidencialidad, fue sustancial en la obtención de datos; a ella debemos nuestro mayor agradecimiento. Asimismo, esta propuesta se desarrolló como parte del proyecto grupal de Cátedras CONACyT titulado "El binomio Identidad/ Pobreza y su expresión en la salud y el bienestar alimentario” del CIESAS-Unidad Peninsular.

\section{Bibliografía}

Bender, Donald R., (1967). "A Refinement of the Concept of Hosehold: Families, Co-residence and Domestic Functions”. American Anthropologyst, No. 69. p. 493-504.

Berman, Peter, Carendall y Karabi Bhattacharyya, (1994). "The household production of health: integrating social science perspectives on micro-level health determinants". Social Science and Medicine 38, $\mathrm{n}^{\circ} 2$ (enero). p. 205-215.

Farmer P., (2001). "Desigualdades Sociales y Enfermedades Infecciosas Emergentes". Revista Facultad Nacional de Salud Pública. 19(2), URL: http://www.redalyc.org/articulo. oa?id=12019211

Freyermuth Enciso, Graciela, (1993). Médicos tradicionales y médicos alópatas. Un encuentro difícil en los Altos de Chiapas. Tuxtla Gutiérrez: CIESAS, Gobierno del Estado de Chiapas.

Hareven, Tamara, (1974). "The family as process: the historical study of the family cycle" en Journal of Social History (Cambridge) Vol. 7, N 3 . 
Ibañez-Bernal S y H. Gómez-Dantés H, (1995). "Los vectores del dengue en México: una revisión crítica”, en: Salud Pública Mex, vol.37, suppl. p. 53-63.

Kleinman, Arthur, (1988). The Illness Narratives. Suffering, Healing, and the Human Condition. EUA: Perseus.

Lerín, Sergio, (2994). "Antropología y salud intercultural: desafíos de una propuesta”. Desacatos, CIESAS: México, No. 15-16 (Otoño-invierno). p. 111-125.

Menéndez, Eduardo, (1992). "Modelo hegemónico, modelo subordinado, modelo de autoatención. caractéres estructurales”. La antropología médica en México. Eduardo Menéndez (coord). México: UAM. p. 97-113.

Menéndez, Eduardo, (1994). “La enfermedad y la curación ¿qué es la medicina tradicional?”. Alteridades, 4 , No. 7. p. 71-83.

Menéndez, Eduardo, (2009). De sujetos, saberes y estructuras. Introducción al enfoque relacional en el estudio de la salud colectiva. Buenos Aires: Editorial Lugar.

Modena, María Eugenia, (1990). Madres, médicos y curanderos. México: CIESAS.

Osorio Carranza, Rosa María, (2001). Entender y atender la enfermedad: los saberes maternos frente a los padecimientos infantiles. México: CIESAS.

Quattrocchi P, Miguel Güemez Pineda, (2007). Salud reproductiva e interculturalidad en el Yucatán de hoy. México: Universidad Nacional Autónoma de México.

Robichaux, David, (2007). "Sistemas familiares en culturas subalternas de América Latina: una propuesta conceptual y un bosquejo preliminar". En Familia y Diversidad en América Latina. Estudios decasos. David Robichaux (coordinador), Buenos Aires: CLACSO, Consejo Latinoamericano de Ciencias Sociales.

Rosen, George, (2005). De la policía médica a la medicina social. México: Siglo veintiuno Editores.

Sacchi, Mónica, Margarita Hausberger y Adriana Pereyra, (2007). "Percepción del proceso saludenfermedad-atención y aspectos que influyen en la baja utilización del sistema de salid en familias pobres de la ciudad de Salta". Salud Colectiva 3, nº 3 (septiembre-diciembre), p. 271-283.

Salvatella Agrelo, Roberto, (1996). "Aedes aegypti, Aedes albopictus (Diptera, Culicidae) y su papel como vectores en las Américas”, Sindicato Médico del Uruguay. URL: http://www.bvsde. paho.org/bvsasv/fulltext/aede.pdf

Scott DL, Wolfe F, Huizinga TW., (2010). "Rheumatoid arthritis". Lancet. No. 25; 376(9746), (sept.), p. 1094-1108. URL: www.ncbi.nlm.nih.gov/pubmed/20870100.

Segalen, Martien, (1992). Antropología histórica de la familia, Editorial Taurus: Madrid.

Sesia, Paola, (1992). "La obstetricia tradicional en el itsmo: marco conceptual y diferencias con el modelo biomédico". Medicina tradicional, herbolaria y salud comunitaria en Oaxaca, Paola Sesia (coord.). Oaxaca: CIESAS, Gobierno del Estado de Oaxaca. p.17-54.

Setbon, Michel, Jocelyn Raude y Dana Pottratz, (2008). "Chikungunya on Réunion Island: Social, Environmental and Behavioural Factors in an Epidemic Context", Population, INED, vol 63, No. 3 (jul-sept). p. 491-518.

Spinelli, Hugo, (2016). "Dengue y Zika, Baja mortalidad, alta desigualdad”, Revista Anfibia, Universidad Nacional de San Martín, URL: http://www.revistaanfibia.com/

Stein, Marina; Oria, Griselda I; Almiron, Walter R y Willener, Juana A, (2005). "Fluctuación estacional de Aedes aegypti en Chaco, Argentina". Rev. Saúde Pública, Vol. 39(4), p. 559-564.

Yanagisako, Sylvia Yunko, (1979). "Family and Hosuehold: The Analisis of Domestic Groups”, en Annual review of Anthropology, Vol 8, pp. 161-205.

\section{3}

